\title{
Resistance to antibiotics of Escherichia Coli, Enterobacter Gergoviae and Klebsiella Pneumoniae during urinary infections at CHUJRA Antananarivo, Madagascar
}

\author{
Andrianarivelo A.M. ${ }^{1}$, Ratsimbazafy A.B.A. ${ }^{2}$, Ravaoarisaina Z.M. ${ }^{3}$, Rafaramalala S.S., Razanadrakoto I.I. ${ }^{4}$, \\ Rakotondraoelina L.M. ${ }^{6}$, Raharisoa A.A. ${ }^{7}$, Rafalimanana C. ${ }^{8}$, Rasamindrakotroka A. ${ }^{9}$ \\ ${ }^{1}$ Andry Maharo Andrianarivelo, ${ }^{2}$ Arthur Bien Aimé Ratsimbazafy, ${ }^{3}$ Zakasoa Mbololona Ravaoarisaina, ${ }^{4}$ Solofo Sarah \\ Rafaramalala, ${ }^{5}$ Ianja Iorenantsoa Razanadrakoto, ${ }^{6}$ Lalaina Mamenosoa Rakotondraoelina, ${ }^{7}$ Annie Armandine Raharisoa, \\ ${ }^{8}$ Christian Rafalimanana, ${ }^{9}$ Andry Rasamindrakotroka; all authors are attached with Laboratory of Training and Research in \\ Medical Biology, University of Antananarivo, Madagascar
}

Corresponding Author: Dr Andrianarivelo Andry Maharo, Laboratory of Training and Research in Medical Biology, University of Antananarivo, Madagascar, BP 4150. E-mail: andrimaharo@gmail.com

\begin{abstract}
Introduction: Infections of the urinary tract remain among the most common problems facing the clinician. This work aims to determine the antibiotic resistance of E. coli, E. gergoviae and K. pneumoniae during urinary tract infections in the Microbiology laboratory of the Joseph Ravoahangy Andrianavalona Antananarivo University Hospital Center to allow a better therapeutic approach. Material \& Methods: We carried out a retrospective and descriptive study on all of the E. coli, E. gergoviae and K. pneumoniae strains isolated from the urine of patients who attended the laboratory of Microbiology on CHUJRA Antananarivo with a suspected UTI between January 2004 and december 2014. Susceptibility to antibiotics was assessed by the disc diffusion technique on Mueller-Hinton agar (MH) or $\mathrm{MH}+5 \%$ sheep blood, as recommended by the Antibiogram Committee of the French Microbiology Society as the antibiotics tested. Results: E. coli, E. gergoviae and K. pneumoniae were isolated from 577 of the 5836 patients who submitted a urine sample (9.89\%). Almost three quarters of isolates were E. coli (72.96\%), E. gergoviae was found in $7.80 \%$ of cases and K. pneumoniae in $19.23 \%$ of cases.Ampicillin, amoxicillin + clavulanic acid, ticarcillin, first generation cephalosporins, second generation cephalosporins, cyclins, and cotrimoxazole represent a very high resistance level for E. coli, E. gergoviae and K. pneumoniae in the vast majority of cases. Since 2008, the presence of ESBL has been lower than in previous years $(\mathrm{p}=0.02)$. Antibiotics that remain effective in the majority of UTI cases are nitrofurans, colistin, imipenem, amikacin and Piperacillin / tazobactam. Conclusions: These results confirm the presence of multi- resistant strains as in hospitals and community settings and the associated resistance to the most accessible antibiotics inevitably limits the choice of antibiotic in the establishment of adequate treatment.
\end{abstract}

Keywords: Resistance, Antibiotics, ITU, CHUJRA Antananarivo

\section{Introduction}

Infections of the urinary tract remain among the most common problems facing the clinician. It is remarkable because of the different clinical varieties related to different topographic sites of infection and broad concept, ranging from asymptomatic infection to pyelonephritis with sepsis. Cause identification and severity of infection are generally established through the evaluation of clinical presentation, biochemical and urinary cultures. They are common in both community and hospital settings. They represent more than $40 \%$ (always increasing proportion) of nosocomial infections [1]. This frequency is related to favoring factors and uropathogenicity factors of the germs in question [2].

Manuscript received: $27^{\text {th }}$ September 2019

Reviewed: $8^{\text {th }}$ October 2019

Author Corrected: $13^{\text {th }}$ October 2019

Accepted for Publication: $18^{\text {th }}$ October 2019
However, excessive use of antibiotics including broad spectrum in other conditions contributes to the development of resistance in bacteria responsible for urinary tract infection and causes difficulty in the treatment of these. Levels of bacterial resistance vary from country to country and from year to year. Also, knowledge of the local situation and its evolution are necessary for the choice of antibiotic therapy for first-line. Very little study concerning the antimicrobial resistance of bacteria isolated from urinary tract infections in Antananarivo have been published to date. However, with the emergence of resistant urinary pathogens observed in certain community and hospital settings, a change of practice in the management of patients is to be considered thus requiring a revision of the choices.

Pathology Update: Tropical Journal of Pathology \& Microbiology Available online at: www.medresearch.in 850 | P a g e 
All bacterial strains are not capable of inducing a urinary tract infection, some strains have specific virulence factors allowing rapid diffusion from the faecal flora to the renal parenchyma.

These are enterobacteria represented mainly by Escherichia coli, as well as Enterobacter gergoviae and Klebsiella pneumoniae. This work aims to determine the antibiotic resistance of E. coli, E. gergoviae and K. pneumoniae during urinary tract infections in the Microbiology laboratory of the Joseph Ravoahangy Andrianavalona Antananarivo University Hospital Center (CHUJRA) to allow a better therapeutic approach.

\section{Methods}

Study design: The present study was a retrospective and descriptive study on all of the E. coli, E. gergoviae and $K$. pneumoniae strains isolated from the urine.

Study setting: Patients who attended the laboratory of Microbiology on CHUJRA Antananarivo with a suspected urinary tract infection.

Duration of study: between January 2004 and December 2014.

\section{Results}

E. coli, E. gergoviae and K. pneumoniae were isolated from 577 of the 5836 patients who submitted a urine sample $(9.89 \%)$. Among them, 413 were women and 164 were men (mean age 28.4 years, range $0-77$ years, sex ratio 0.40 ).

There was no significant difference concerning the species according to age classes or gender. Almost three quarters of isolates were E. coli $(72.96 \%)$, E. gergoviae was found in $7.80 \%$ of cases and K. pneumoniae in $19.23 \%$ of cases (Table 1).

Ampicillin, ticarcillin, cyclins, and cotrimoxazole represent a very high resistance rate for $E$. coli with respectively $89.07 \%$, $87.38 \%, 76.43 \%$, and $75.77 \%$ of cases. Regarding the antibiotic resistance of $K$. pneumoniae, amoxicillin + clavulanic acid, first-generation cephalosporins $(\mathrm{C} 1 \mathrm{G})$, cyclins, and cotrimoxazole represent a very high resistance rate in almost all cases with respectively $88.29 \%, 88.29 \%, 91.89 \%$, and $91.89 \%$.

Ticarcillin, cyclins, cotrimoxazole and second-generation cephalosporins $(\mathrm{C} 2 \mathrm{G})$ represent a very high resistance rate for $E$. gergoviae with $85.71 \%, 82.22 \%, 86.36 \%$ and $82.22 \%$ respectively (Table 2 ). There was no significant difference concerning the species according to the provenance and antibiotics sensibility.

R: resistant, S: sensible, Amoxi-clav: amoxicillin + clavulanic acid, C1G: first-generation cephalosporins, C2G: secondgeneration cephalosporins, C3G: third generation cephalosporins, Pipe/tazo: piperacillin/tazobactam

E. coli, K. pneumoniae and E. gergoviae secretory ESBL were found in 54 cases, 38 cases and 22 cases, respectively whether $19.76 \%$ of cases of diagnosed urinary tract infection.ESBL producing to $E$. coli is more common in the community ( 38 cases, or $59.37 \%$ ) while in hospital, K. pneumoniae and E. gergoviae produce more ESBL with 28 case (65.11\%) and 18 case (69.23\%) respectively.

The presence of very high rate of E. coli, K. pneumoniae and E. gergoviae secreted by ESBL was noted during the years 2004 until 2007. Then this rate decreases since 2008 and then stabilizes for the rest of the years. This result is significant ( $\mathrm{p}=0.02)$. 
Table-1: Distribution by the provenance of the sample.

\begin{tabular}{|c|c|c|c|c|}
\hline Germs & Hospitalised (n) & Communautary (n) & \multicolumn{2}{|c|}{ Total (n/\%) } \\
\hline Escherichia coli & 181 & 240 & 421 & 72.96 \\
\hline Enterobacter gergoviae & 26 & 19 & 45 & 7.80 \\
\hline Klebsiella pneumoniae & 65 & 46 & 111 & 19.23 \\
\hline
\end{tabular}

Table-2: Antibiotic susceptibility of strains of E. coli, K. pneumoniae, and E. gergoviae.

\begin{tabular}{|l|c|c|c|c|c|c|}
\hline \multirow{2}{*}{ Antibiotics } & \multicolumn{2}{|c|}{ E. coli } & \multicolumn{2}{c|}{ K. pneumoniae } & \multicolumn{2}{c|}{ E. gergoviae } \\
\cline { 2 - 7 } & $\mathrm{R}(\mathrm{n} / \%)$ & $\mathrm{S}(\mathrm{n} / \%)$ & $\mathrm{R}(\mathrm{n} / \%)$ & $\mathrm{S}(\mathrm{n} / \%)$ & $\mathrm{R}(\mathrm{n} / \%)$ & $\mathrm{S}(\mathrm{n} / \%)$ \\
\hline Ampicillin & $375(89.07)$ & $46(10.93)$ & $111(100)$ & 0 & $45(100)$ & 0 \\
\hline Ticarcilin & $368(87.38)$ & $53(12.62)$ & $111(100)$ & 0 & $45(100)$ & 0 \\
\hline Amoxi-clav & $286(67.93)$ & $135(32.07)$ & $98(88.29)$ & $13(11.71)$ & $45(100)$ & 0 \\
\hline C1G & $299(71.02)$ & $122(28.98)$ & $98(88.29)$ & $13(11.71)$ & $45(100)$ & 0 \\
\hline C2G & $173(41.09)$ & $247(58.71)$ & $74(66.67)$ & $37(33.33)$ & $37(82.22)$ & $8(17.78)$ \\
\hline C3G & $64(15.09)$ & $357(84.91)$ & $43(38.74)$ & $68(61.26)$ & $26(57.77)$ & $19(42.23)$ \\
\hline Nitrofuran & $18(4.29)$ & $402(95.71)$ & $12(10.81)$ & $99(89.19)$ & $4(8.89)$ & $41(91.11)$ \\
\hline Gentamicin & $71(16.86)$ & $350(83.41)$ & $36(32.43)$ & $75(67.57)$ & $23(51.11)$ & $22(48.89)$ \\
\hline Tobramycin & $71(16.86)$ & $350(83.41)$ & $36(32.43)$ & $75(67.57)$ & $24(53.33)$ & $21(46.67)$ \\
\hline Netilmycin & $71(16.86)$ & $350(83.41)$ & $36(32.43)$ & $75(67.57)$ & $24(53.33)$ & $21(46.67)$ \\
\hline Kanamycin & $75(17.81)$ & $346(88.19)$ & $46(41.44)$ & $65(58.56)$ & $26(57.78)$ & $19(42.22)$ \\
\hline Fluoroquinolone & $167(39.67)$ & $254(60.33)$ & $82(73.87)$ & $29(26.13)$ & $35(77.78)$ & $10(22.22)$ \\
\hline Cyclins & $321(76.43)$ & $99(23.57)$ & $102(91.89)$ & $9(8.11)$ & $37(82.22)$ & $8(17.78)$ \\
\hline Cotrimoxazole & $319(75.77)$ & $102(24.23)$ & $102(91.89)$ & $9(8.11)$ & $38(86.36)$ & $7(13.64)$ \\
\hline Chloramphenicol & $44(10.53)$ & $374(89.47)$ & $23(20.91)$ & $87(79.09)$ & 0 & $45(100)$ \\
\hline Amikacin & $3(0.71)$ & $417(99.29)$ & 0 & $111(100)$ & 0 & $45(100)$ \\
\hline Pipe/tazo & $10(2.51)$ & $388(97.49)$ & $4(3.67)$ & $107(95.41)$ & 0 & $45(100)$ \\
\hline Colistin & 0 & $420(100)$ & $3(2.70)$ & $108(97.30)$ & $32(85.71)$ & $5(14.29)$ \\
\hline Imipenem & 0 & $420(100)$ & 0 & $111(100)$ & $12(25)$ & $33(75)$ \\
\hline
\end{tabular}

Antibiotics that remain effective in most cases of urinary E. coli, K. pneumoniae, and E. gergoviae infections have been nitrofuran, colistin, imipenem, amikacine and piperacillin/tazobactam (Table 2).

\section{Discussion}

The study focuses on the antibiotic resistance of $E$. coli, $K$. pneumoniae and E. gergoviae isolated from urinary tract infection because urinary tract infection is still a very common infection with an incessant increase in resistance to certain antibiotics [4].

Among the bacteria studied, E. coli is isolated in almost three quarters of cases in hospitalized patients or not (Table 1). Ampicillin, amoxicillin + clavulanic acid, ticarcillin, first generation cephalosporins $(\mathrm{C} 1 \mathrm{G})$, second generation cephalosporins (C2G), cyclins, and cotrimoxazole represent a very high resistance level for E. coli, $E$. gergoviae and $K$. pneumoniae in the vast majority of cases (Table 2). Some data from the literature confirm that nosocomial or community urinary tract infections represent an increase in antibiotic resistance. This would be due to the misuse of antibiotics because it is possible that exposure to another family of antibiotics may select bacteria resistant to other families of antibiotics by cross mechanisms [5]. These results confirm the presence of multiresistant strains as in hospitals and community settings and the associated resistanceto the most accessible antibiotics inevitably limits the choice of antibiotic in the establishment of adequate treatment. Moreover, the worrying resistance to amoxicillin-clavulanic acid association are described in the treatment of first resort hinders the empiric antibiotic therapy of urinary tract infection [6].

However, studies of a larger population need to be undertaken to statistically support these findings and to evaluate other risk factors and the determinants of the carriage of these multidrug-resistant bacteria in community and hospital settings. The emergence of strains of thirdgeneration cephalosporin-resistant bacteria that are the 
ESBLs that constrain the treatment of infection is today a scourge known by several countries including Madagascar [7]. This resistance, more commonly known by ESBL, constitutes a very large heterogeneous family of bacterial enzymes which inactivates most beta-lactams except cephamycins and carbapenems. They are most often of plasmid origin, which explains their rapidity of diffusion and evolution [8]. This constantly increasing resistance must attract the attention of all treating physicians because if it is poorly controlled, this could lead to several complications such as irreversible kidney damage, severe sepsis and could even lead to death of the patient [5].

The studies carried out in Antananarivo by Ramilitiana B. and al which found a rate of ESBL at $8.3 \%$ or that of Rasamiravaka T. and al, which show an ESBL level at $11.7 \%$, confirm the results of the present study [7,9]. A study by Shekshok Y. et al showed a high level of C3Gresistant Klebsiella pneumoniae (62\%), which would be a consequence of the selection pressure due to the wide use of B-lactam antibiotics and furthermore, these resistances acquired from made of their plasmid determinism, have a great power of dissemination [10]. ESBL-producing E. coli is more common in the community (59.37\% of cases) while in hospital, K. pneumoniae and E. gergoviae produce more ESBL. Some data from previous studies or those in the literature show that E. coli is the main pathogen of nosocomial or community urinary tract infection, an increase in antibiotic resistance [5].

These ESBL infections are a public health problem as many are of community origin. The approach must therefore be multidimensional and integrate two components that are the improvement of standard precautions and the rationalization of antibiotic consumption and their prescription following the protocols established in Madagascar because the first-line treatment may vary depending on realities of each country $[9,11]$.

Nitrofurans, colistin, imipenem, amikacin and Piperacillin / tazobactam are the antibiotics that remain effective in cases of urinary tract infection found in the present study. A study by Y. Sekhsokh and al states that ESBL-producing bacteria are resistant to the majority of antibiotics but retain a high sensitivity to imipenem and amikacin [10]. This is the recognized and undisputed treatment of with ESBLproducing enterobacteria is based on carbapenems, but the place of the other molecules remains to be debated. Indeed, in the current threatening epidemiological situation, no molecule can be ruled out, if only to diversify the prescribed antibiotherapies.

The variability of the problems posed by the ESBLproducing bacteria implies the establishment of a national surveillance network, the microbiology laboratory playing a key role in the detection and monitoring of resistance. Indeed, it is important to understand the extent and development of antibiotic resistance over time to manage this problem. To control antibiotic resistance, it is clear that reliability can no longer be on the development of new molecules whose prospects are very limited, but it is possible to slow the development of resistance by prevention strategies. Prevention of the emergence of resistance and diffusion of ESBL secretory bacteria represents a major public health issue for health care institutions. This rise in resistance is generally correlated with, among other things, an increase in antibiotic consumption as suggested by Grude et al. [12]. In Morocco, the consumption of antibiotics increased by $42 \%$, according to El Mdaghri et al. [13], hence the importance of raising awareness of the proper use of antibiotics and monitoring to control the spread of antibiotic resistance.

The likely relationship between resistance and high antibiotic consumption on the one hand, the insufficient application of standard hygiene precautions to limit crosstransmission of ESBL on the other, favor this phenomenon [14].

It is therefore necessary to implement strategies to control these pathogens. The fight can be articulated around three main objectives such as the control of the spread of ESBL by cross-transmission, the prevention of the emergence of ESBL linked to the too wide, too abusive use of antibiotics.

Also, it is necessary to spread to the entire medical world (doctors, dentists, midwives and paramedics, employees and liberals) training and information on the epidemic spread of ESBL secretory enterobacteria, which exposes, ultimately, the risk of therapeutic impasse.

All microbiologists must also be made aware of the problem of the epidemic spread of ESBL-secreting enterobacteria and their resistance genes, and the means that must be used to identify this type of resistance. The information will focus on the risk of cross-transmission of these bacteria and their resistance genes, whose natural reservoir is mainly digestive and urinary. A strong presence of $E$. coli, $K$. pneumoniae and $E$. gergoviae secretory by ESBL was found from 2004 to 2007, then this rate decreased significantly since 2008 and stabilized thereafter. At the national level in Madagascar, real access to medicines began in 2007 as part of the national health policy which was associated with strengthening the training of health personnel in quality and quantity with adequate staff distribution qualified in all health centers. This measure is to ensure at least $85 \%$ availability and accessibility of essential drugs, medical consumables, reagents in all health facilities by extending the range of Salama (essential drug supplier) for drugs and consumables hospitals. 
This has been accompanied by a rationalization of the prescription and also the rational use of medicines with the objective of improving the health system in Madagascar until 2011. Better access to medicines and their rational prescription in a hospital environment can explain the decrease of the ESBL found in our center during the year 2008. However, the private practices, which escape the trainings and supervisions of the Ministry of Health, continued in the irrational prescription of the drugs, in particular the antibiotics [15].

The decrease of the pharmacological pressure by the changes made at the level of protocols probably led to the decrease of the resistances. Several studies have reported decreases in resistance following the suppression or restriction in the prescription of certain antibiotics [16].

A survey conducted by Raisin France has determined an increase in EBLSE from 38\% in 2006 to $60 \%$ in 2012 and for the same reasons that have been mentioned previously [17]. At the national level, epidemiological surveillance of ESBL-secreting enterobacteria must be ensured. Specific studies should be considered to complete this scheme.

However, this study has limitations because the samples are not representative of all the cases of urinary infection that could be encountered throughout Madagascar.

\section{Conclusion}

In almost all cases, ampicillin, amoxicillin + clavulanic acid, ticarcillin, first-generation cephalosporins, secondgeneration cephalosporins, cyclins, and cotrimoxazole represent a resistance very high rate for E. coli, E. gergoviae and $K$. pneumoniae. Since 2008, the presence of ESBL has been lower than in previous years. Antibiotics that remain effective in the majority of UTI cases are nitrofurans, colistin, imipenem, amikacin and Piperacillin / tazobactam. The increasing strength of community and hospitalacquired strains of E. coli, E. gergoviae and K. pneumoniae antibiotics has become an alarming phenomenon in Antananarivo.

This encourages reflection on the management of patients consulting for urinary tract infection. To avoid the occurrence of resistance to these molecules, it would be wise to have the results of the bacteriological examination before prescribing them.

The rules of antibiotic prescriptions and the introduction of antibiotic prophylaxis should also be applied to limit the scourge of ESBL secretory bacteria. Indeed, the treatment of urinary tract infections should be reconsidered and be the subject of a therapeutic consensus taking into account the national situation of antibiotic resistance.

\section{What the study adds to the existing knowledge?}

The data obtained from the present study can be used to determine trends in antimicrobial resistance of E. coli, E. gergoviae and $K$. pneumonia during community or nosocomial urinary tract infections and to reformulate the antibiotics to be prescribed. This will assist clinicians in the rational selection of antibiotic therapy for effective management of patients.

\section{Author's contribution}

- Andry Maharo Andrianarivelo: Concept, design, preparation and editing of manuscript.

- Arthur Bien Aimé Ratsimbazafy: Preparation and editing of manuscript.

- Zakasoa Mbololona Ravaoarisaina: Preparation and editing of manuscript, literature search.

- Solofo Sarah Rafaramalala: Data Collection, data compiling.

- Ianja Iorenantsoa Razanadrakoto: Data collection, data compiling.

- Lalaina Mamenosoa Rakotondraoelina: Data collection and data analysis.

- Annie Armandine Raharisoa: Assisted in data analysis.

- Christian Rafalimanana: Final approval

- Andry Rasamindrakotroka: Final approval

Funding: No funding sources

Conflict of interest: None declared

Ethical Approval: This study was approved by the Institutional Ethics Committee

\section{Reference}

1. Dracon M, Lemaitre L. Urinary infection of children and adults - Leucocyturia. The practitioner's review. 2003;53 (10):1137-1142.

2. Alvarez C, Pangon B, Allouch PY, Ghnassia JC. Infections urinaires : principaux aspect épidémiologiques, bactériologiques et cliniques. Feuillets Biol. 1992;23 (189):15-24.

3. Skov R, Smyth R, Larsen AR, Bolmstrom A, Karlsson A, Mills K, Frimodt-Moller N. Antibiogram Committee of the French Society of Microbiology. SFM Recommendations 2007. 2007.

4. Ramilitiana B, Rakotoarivelo RA, Razafimahefa $\mathrm{SH}$, Vololontiana D, Randrianarison A, Randria MJD et al. Prévalence de la résistance des bactéries aux antibiotiques dans les infections urinaires de l'adulte en milieu hospitalier à Antananarivo. Med Afr Noire. 2014 ;61(10):514-518. 
5. Carron F, Galperine T, Dumarcet N, Azria R, Bingen E, Botto $\mathrm{H}$ et al. Diagnostic et antibiothérapie des IU bactériennes communautaire chez l'adulte. Elsevier Masson : médecine et maladies infectieuses. 2008:203-252.

6. Bourquia A, Ramdani B, Sahni K, Zaid D. Profile of urinary tract infection in a Nephrology department. Maghreb Med. 1992;33:11-12.

7. Randrianirina F, Soares JL, Carod JF, Ratsima E, Thonnier V, Combe P, et al. Antimicrobial resistance amonguropathogens that cause community-acquired urinary tract infections in Antananarivo, Madagascar. J Antimicrob Chemother. 2007;59 (2):309-312. doi : https://doi.org/10.1093/jac/dk1466.

8. Vora S, Auckenthaler R. Que signifie « Béta-lactamaseà spectre élargi » en pratique? Rev Med Suisse. 2009; 5:1991-1994.

9. Rasamiravaka T, Rafanomezantsoa H, Rasoanandrasana S, Rakoto Alson AO, Rasamindrakotroka A. Présence préoccupante des bactéries multirésistantes dans la société malgache. Revue médicale de Madagascar. 2012; 2 (3):174-175.

10. Sekhsokh Y, Shaldy M, Hamzaoui E et al. Fréquence et sensibilité aux antibiotiques des bactéries isolées dans les urines. Médecine et maladies infectieuses. 2008;38(6):324327.

11. Zahar J, Mamzer M, Kouatchet A. Contact isolation in the intensive care unit: why, when and adverse effects. Reanimation. 2011; 21(suppl 2):494-502
12. Grude N, TvetenY, Kristiansen B-E. Urinary tract infections in Norway: bacterialetiology and susceptibility. A retrospective study of clinical isolates. Clin Microbiol Infect.2001;7(10):543-547.

13. El Mdaghri N, Belaïche A, Messaouidi D, Perrier-GrosClaude JD, Benbachir M. Consommation d'antibiotiques et résistance des souches d'Escherichia coli isolées d'infections urinaires communautaires au Maroc. RICAI nos 1 et 2 décembre2005. 2005; Communication:101-240.

14. Levent T, Gauthier M, Dezorzi S, Paradis P, Alibert J, Bettoni C, Stock B. L'hygiène hospitalière et le conseil en antibiothérapie: un duo opérationnel face au problème de la diffusion des bactéries multirésistantes aux antibiotiques. Médecine et maladies infectieuses. 2005;35(9):443-449.

15- Ministère de la Sante, du planning familial et de la protection sociale de Madagascar. Plan de développement secteur sante 2007-2011. Ministère de la Sante, du planning familial et de la protection sociale de Madagascar. 2007.

16. Landman D, Chockalingam M, Quale JM. Reduction in the incidence of methicillin-resistant Staphylococcus aureus and ceftazidime-resistant Klebsiella pneumoniae following changes in a hospital antibiotic formulary. Clin Infect Dis. 1999;28(5):1062-1066. doi: 10.1086/514743.

17. Réseau BMR-Raisin. Réseau d'alerte, d'investigation et de surveillance des infections nosocomiales (raisin), surveillance des bactéries multi-résistantes dans les établissements de santé en France. Institut de veille sanitaire. 2012. http//www.invs.sante.fr/bmr-raisin.

\section{How to cite this article?}

Andrianarivelo A.M., Ratsimbazafy A.B.A., Ravaoarisaina Z.M., Rafaramalala S.S., Razanadrakoto I.I., Rakotondraoelina L.M., Raharisoa A.A., Rafalimanana C., Rasamindrakotroka A. Resistance to antibiotics of Escherichia Coli, Enterobacter Gergoviae and Klebsiella Pneumoniae during urinary infections at CHUJRA Antananarivo, Madagascar. Trop J Path Micro 2019;5(11): 850-855.doi:10.17511/jopm. 2019.i11.03 